\title{
Thyroid disease following the administration of Thorotrast
}

\author{
A. O. LANGLANDS AND KATE HERMANN \\ From the M.R.C. Clinical Effects of Radiation Research Unit, Western General Hospital, Edinburgh, and the \\ Department of Surgical Neurology, Edinburgh Royal Infirmary, and Western General Hospital, Edinburgh
}

SYNOPSIS Four cases of thyrotoxicosis are reported among 35 patients who had been given Thorotrasto during the investigation of intracranial haemorrhage. For the group as a whole Thorotrast had ${ }_{0}^{\circ}$ been given between 11 and 31 years (mean 23.4 years) before this study. Thyrotoxicosis ${ }_{0}^{N}$ occurred in four patients between six and 17 years (mean 11.8 years) after the injection of Thorotrast. The fact that thyrotoxicosis did not occur in a small control group of patients who had $\vec{Z}$ had a subarachnoid haemorrhage and in whom Thorotrast had not been used at angiographyo suggests that Thorotrast may be of aetiological significance. In view of the known association $\frac{\Phi}{3}$ between thyrotoxicosis and changes in the lymphoreticular system it is possible that the irradiation of this system by retained thorium has resulted in an abnormality of function which renders these patients more liable to the development of thyrotoxicosis.

A fifth patient developed non-toxic thyroid enlargement 16 years after Thorotrast angiography.

Knowledge concerning the biological effects in man of small body burdens of radioactive material is limited, and is virtually confined to studies on persons, such as luminizers, who have ingested radium, or patients who have received Thorotrast during clinical investigation in the past. Thorotrast, a colloidal suspension of ${ }^{232}$ thorium dioxide, was extensively used as a radiographic contrast medium between 1930 and 1947 when its use was largely abandoned following the report of the first malignancy attributable to this compound (MacMahon, Murphy, and Bates, 1947).

Many investigators have been concerned in assessing the risk of the development of malignant disease in internally irradiated populations. For example, it is now known that an increased incidence of osteogenic sarcoma is associated with body burdens of radium in excess of $0.4 \mu \mathrm{c}$. (Dunham, 1958) and haemangioendothelioma of the liver is virtually a Thorotrast-specific tumour (Horta, Abbatt, da Motta, and Roriz, 1965). In contrast, there is little or no information concerning the incidence of diseases, other than malignancies, in populations exposed to internal radiation. A reason for this may be that much of the research is concerned with the study of causes of death.

We have recently examined 35 patients who had

Received for publication 24 January 1967. received intra-arterial Thorotrast. In this group of patients there was a higher incidence of thyroid\% disease than might have been expected by chance. 0 The purpose of this paper is to draw attention to this $\overrightarrow{\vec{O}}$ finding and to give details of five cases.

\section{MATERIAL}

During investigation in the Department of Surgical. Neurology, Edinburgh, 137 patients received intraarterial? Thorotrast, usually in the course of carotid angiography. In 1966, 37 survivors were still residing in Edinburgh orô nearby. Of these, 35 (18 men and 17 women) were inter viewed.

Control information on the incidence of thyroid disease was obtained from the replies to a questionnaire sent too the general practitioners of patients who had not been exposed to Thorotrast.

\section{RESULTS}

Two men and two women developed thyrotoxicosis after the injection of Thorotrast. A third woman? developed non-toxic thyroid enlargement.

These patients do not differ, with respect to diagnosis or the reason for angiography, from the remaindero of the series. In over $80 \%$ of the cases angiographyd was carried out following a diagnosis of subarach $\frac{}{\mathrm{D}}$ noid haemorrhage. In cases 1 to 4 the diagnosis of 
subarachnoid haemorrhage was confirmed, either by the finding of bloodstained fluid on lumbar puncture or by the demonstration of a congenital arterial aneurysm following angiography. The diagnosis of subarachnoid haemorrhage in case 5 was presumptive.

No cases of thyrotoxicosis occurred among 10 men and 12 women in an average follow-up time of 14 years following subarachnoid haemorrhage and in whom angiography had been carried out using a contrast medium other than Thorotrast. In this control group one woman developed thyroid deficiency due to hypopituitarism following subarachnoid haemorrhage.

Apart from case 3 the amount of Thorotrast injected in the cases developing thyroid disease is not significantly different from the mean value of $25.5 \mathrm{ml}$. based on 30 cases where the dosage was accurately known.

The details of these cases are as follows.

\section{CASE REPORTS}

CASE 1 G.C., a man aged 55, at the age of 35 was investigated after a series of episodes with the characteristic symptoms of spontaneous intracranial haemorrhage into the subarachnoid space and into the left temporal lobe. A total of $36 \mathrm{ml}$. of Thorotrast was injected during bilateral carotid angiography. At craniotomy a large saccular aneurysm was found at the junction of the left internal carotid artery and the posterior communicating artery. This was dealt with by the application of clips to the neck of the aneurysm. No treatment was undertaken for a possible, second, small aneurysm at the junction of the right internal carotid artery and the ophthalmic artery. He made a good recovery apart from some residual dysphasia.

In 1963, following an attack resembling angina pectoris, the patient was treated with digoxin and potassium iodide. In June 1964 he was admitted to hospital complaining of increasing breathlessness, nausea, and abdominal discomfort, and was found to have a spontaneous pneumothorax. In addition, there was atrial fibrillation. The isthmus of the thyroid gland was enlarged.

Tests for thyroid antibodies were negative. The uptake of ${ }^{131} \mathrm{I}$ at four hours was $65 \%$. The $\mathrm{T}_{3}$ absorption test was in the hyperthyroid range. Liver function tests showed a consistent reversal of the $A / G$ ratio (albumin $3.2 \mathrm{~g} . \%$, globulin 3.1 g. \%). Alkaline phosphatase was 24 K.A. units, S.G.O.T. 29 units, S.G.P.T. 23 units.

The patient was treated with $6 \mathrm{mc}$. of ${ }^{131} \mathrm{I}$ and carbimazole and is now euthyroid.

CASE 2 J.S., a man aged 44, at the age of 18 had a spontaneous subarachnoid haemorrhage which produced a right hemiparesis. The diagnosis of subarachnoid haemorrhage was confirmed by lumbar puncture. There is no record of the amount of Thorotrast injected into the left carotid artery and no source of bleeding was visualized. He made a complete recovery and remained well until March 1966, when he developed dyspnoea on exertion, palpitations, tremor of the hands, and weight loss.

On examination the thyroid was found to be generally enlarged but this was more marked on the left side. Protein-bound iodine measured $11.8 \mu \mathrm{g} . / 100 \mathrm{ml}$. Following treatment with methylthiouracil and iodine, subtotal thyroidectomy was carried out. Histologically the diagnosis of hyperthyroidism was confirmed. He is now euthyroid.

CASE 3 C.McK., a woman aged 51, at the age of 30 was admitted to hospital, where a diagnosis of spontaneous subarachnoid haemorrhage was confirmed by lumbar puncture. No abnormality was detected following bilateral carotid and bilateral vertebral angiography, at which a total of $90 \mathrm{ml}$. of Thorotrast was injected.

She made a good recovery and remained well for five years when she developed exophthalmos, tiredness, irritability, palpitations, and weight loss, for which she was admitted to hospital.

Examination revealed a tense, nervous woman with marked exophthalmos. There was generalized enlargement of the thyroid gland. The basal metabolic rate was elevated $(+45 \%)$. Following treatment with phenobarbitone and methylthiouracil she became euthyroid and has remained so.

CASE 4 L.G.H., a woman aged 61, at the age of 49 was investigated following two episodes suggestive of subarachnoid haemorrhage, after the second of which she developed a right third nerve paresis.

A total of $18 \mathrm{ml}$. of Thorotrast was injected during bilateral carotid angiography. Ligation of the right carotid artery in the neck was carried out following the demonstration of a saccular aneurysm at the junction of the right internal carotid artery and the posterior communicating artery.

She remained in good health for nine years, but in 1964 she was admitted to hospital complaining of nervousness, insomnia, and weight loss associated with increased appetite. A history of thyroid enlargement at the age of 16 was elicited.

On examination the thyroid gland was diffusely enlarged and nodular. The palpebral fissures were widened. The uptake of ${ }^{131} \mathrm{I}$ was $74 \%$ at four hours.

Following treatment with two doses of $5 \mathrm{mc}$. of ${ }^{131} \mathrm{I}$ she became euthyroid.

CASE 5 B.V., a woman aged 40 , at the age of 16 was admitted to hospital for the investigation of localized epilepsy and left hemiparesis. At the age of 4, she was thought to have had meningitis but in retrospect this episode could have been due to a subarachnoid haemorrhage. An arteriovenous malformation in the right parietal region was demonstrated following right carotid angiography at which $20 \mathrm{ml}$. of Thorotrast was injected. The malformation was treated by $x$-ray therapy.

Sixteen years after angiography she was referred to hospital with symptomless thyroid enlargement which was more marked on the right side and had been present for one year. A diagnosis of non-toxic goitre was 
TABLE I

DETAILS OF CASES DESCRIBED

\begin{tabular}{|c|c|c|c|c|}
\hline \multirow[b]{2}{*}{ Case } & \multirow[b]{2}{*}{ Sex } & \multirow[b]{2}{*}{$\begin{array}{l}\text { Age } \\
(y r .)\end{array}$} & \multicolumn{2}{|l|}{ Details of Angiography } \\
\hline & & & $\begin{array}{l}\text { Reason for Investigation } \\
\text { and Findings on } \\
\text { Angiography }\end{array}$ & Site(s) of Injection \\
\hline 1 & $\mathbf{M}$ & 35 & $\begin{array}{l}\text { Subarachnoid haemorrhage } \\
\text { Bilateral aneurysms }\end{array}$ & R. + L. carotid \\
\hline 2 & $\mathbf{M}$ & 18 & $\begin{array}{l}\text { Subarachnoid haemorrhage } \\
\text { No abnormality detected }\end{array}$ & L. carotid \\
\hline 3 & $\mathbf{F}$ & 30 & $\begin{array}{l}\text { Subarachnoid haemorrhage } \\
\text { No abnormality detected }\end{array}$ & $\begin{array}{l}\text { R. + L. carotid } \\
\text { R. + L. vertebral }\end{array}$ \\
\hline 4 & $\mathbf{F}$ & 49 & $\begin{array}{l}\text { Subarachnoid haemorrhage } \\
\text { Aneurysm R. int. carotid }\end{array}$ & R. + L. carotid \\
\hline 5 & $\mathbf{F}$ & 16 & $\begin{array}{l}\text { Epilepsy } \\
\text { L. hemiparesis } \\
\text { Arteriovenous malformation }\end{array}$ & R. carotid \\
\hline
\end{tabular}

confirmed at operation when partial thyroidectomy was carried out.

The left hemiparesis persists. Epilepsy is controlled by phenobarbitone. She is euthyroid.

The main features of these cases are summarized in Table 1.

\section{DISCUSSION}

We have been unable to obtain figures for the incidence of thyroid disease in Scotland. Logan and Cushion (1958) have reported the incidence of thyrotoxicosis in England and Wales to be 0.3 and 1.9 per 1,000 for males and females respectively. If one assumes that the corresponding figures for Scotland do not differ significantly from those given by Logan and Cushion the incidence of thyrotoxicosis in our cases is some 16 times greater than expected in males $(P<0.005)$, and some two and a half times greater in females.

There are several features common to the four cases developing thyrotoxicosis. Each suffered a spontaneous subarachnoid haemorrhage, in the course of investigation of which angiography, using Thorotrast, was carried out. No cause for the haemorrhage was demonstrated in two cases and no definitive treatment was undertaken. In the remaining two cases the haemorrhage occurred from an arterial aneurysm which was dealt with surgically.

Angiography, using Thorotrast, was carried out in a fifth patient who subsequently developed non-toxic thyroid enlargement. Although there is no definite history of subarachnoid haemorrhage in this patient an arteriovenous malformation was demonstrated, and was subsequently treated by $x$-ray therapy.

On the basis of four cases, and without fuller investigation, it is not possible to say whether the cases of thyrotoxicosis which developed in this series are aetiologically distinct, although an equal sex
Details of Thyroid Disease

Amount of
Thorotrast
(ml.)

Age at Diagnosis Site of Interval
Onse (yr.)

36

53

Thyrotoxic heart disease $?$

90

18

20

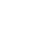

44 Thyrotoxicosis

Isthmus

(yr.)

17

Diffuse

L. $>$ R.

Thyrotoxicosis

Diffuse

Thyrotoxicosis

Diffuse

nodular

Non-toxic

Diffuse

nodular ratio is in contrast to that normally found in large $\stackrel{\circ}{\supset}$ series where the incidence in females is some six times greater than in males (Logan and Cushion, 1958).

In the majority of cases of thyrotoxicosis occurring in this country, the gland shows diffuse hyperplasia. The cases which we are reporting did not differ in this $\mathbb{Q}$ respect. The gland was diffusely enlarged in three $\vec{\circ}$ patients, two of whom had either exophthalmos or lid retraction. In the fourth patient, who presented. with thyrotoxic heart disease, only the thyroid isth-o mus was palpably enlarged.

In common with the remaining cases in the series the patients who developed thyrotoxicosis hado characteristic changes in the peripheral blood, con- $\varrho$ sisting of a disturbance of red cell morphology and $\vec{F}$ the presence of Howell-Jolly bodies in erythrocytes.. These have been reported in detail by Langlands and Williamson (1967) who concluded that, as a result of? radiation by the particles of thorium retained in reticulo-endothelial cells, there was a considerable $e_{-}^{0}$ disturbance of splenic function amounting to atrophy 3 . of that organ. Schur (1908) has also recorded the association of thyrotoxicosis and the presence of 3 Howell-Jolly bodies in the erythrocytes of a patient in whom splenic atrophy was found at post-mortem? examination.

More usually thyrotoxicosis is associated with splenomegaly, and, according to Williams (1962), N this is but one aspect of a more generalized disturb ance of the lymphoreticular system which occurs in an proportion of cases of thyrotoxicosis. This may be manifest as splenomegaly, generalized lymphadenox pathy, thymic enlargement, or peripheral blood changes such as lymphocytosis or neutropenia. The association of thyrotoxicosis and lymphoreticular changes is an intriguing one. Autoantibodies occurin a proportion of cases of thyrotoxicosis and the long-acting thyroid stimulator (L.A.T.S.), for which a pathogenic role has been claimed, is an immuno- 
globulin arising from cells of the lymphoreticular system (McKenzie, 1962).

In the cases which we report, following Thorotrast administration, the evidence for splenic atrophy is indirect and is inferred from peripheral blood changes. Thorotrast is retained by lymphoreticular cells and the possibility of abnormal function of these cells, as opposed to simple loss of function, is worth investigation.

We are grateful to the following: Professor N. M. Dott, Professor F. J. Gillingham, and Mr. J. J. Maccabe for access to their case records and for permission to study their patients, Dr. J. T. Boyd of the M.R.C. Radiation Registry for follow-up information, and to the physicians and surgeons responsible for the management of the thyroid disease occurring in these patients, for permission to publish clinical details.

We also wish to thank Professor W. M. Court Brown, and Dr. W. R. Trotter, of University College Hospital Medical School, London, for their advice on the preparation of this paper.

\section{ADDENDUM}

Since submission of the manuscript a further case of thyroid disease following Thorotrast administra- tion has been seen in a woman of 55. In 1947, at the age of 35 , she suffered a spontaneous subarachnoid haemorrhage, the diagnosis being confirmed by lumbar puncture. No source of bleeding was demonstrated following bilateral carotid angiography when $32 \mathrm{ml}$. of Thorotrast was injected. In 1953, during investigation in hospital for an iron-deficiency anaemia, asymptomatic enlargement of the thyroid gland was noted. When seen in 1967 the thyroid gland remained moderately enlarged, the enlargement affecting mainly the right lobe. Clinically she was euthyroid. The level of protein-bound iodine was $4.3 \mu \mathrm{g} / 100 \mathrm{ml}$. ${ }^{131} \mathrm{I}$ uptake was normal at four hours.

\section{REFERENCES}

Dunham, C. L. (1958). Advanc. biol. med. Phys., 6, 175.

Horta, J. da S., Abbatt, J. D., da Motta, L. C., and Roriz, M. L. (1965). Lancet, 2, 201.

Langlands, A. O., and Williamson, E. R. D. (1967). Brit. med. J., 3, 206.

Logan, W. P. D., and Cushion, A. A. (1958). Morbidity Statistics from General Practice, vol. 1. (General Register Off. Studies on Medicine and Population Subjects, No. 14) H.M.S.O. London. McKenzie, J. M. (1962). J. biol. Chem., 237, 3571.

MacMahon, H. E., Murphy, A. S., and Bates, M. I. (1947). Amer. J. Path., 23, 585.

Schur, H. (1908). Wien. med. Wschr., 58, 441.

Williams, R. H. (1962). Textbook of Endocrinology, 2nd ed. Saunders, Philadelphia and London. 